\title{
A Splenic Epithelial Cyst: Increased Size, Exacerbation of Symptoms, and Elevated Levels of Serum Carcinogenic Antigen 19-9 after 6-year Follow-up
}

\author{
Toru Matsui ${ }^{1}$, Hiroyuki Matsubayashi ${ }^{1}$, Teichi Sugiura ${ }^{2}$, Keiko Sasaki $^{3}$, Hiroaki Ito ${ }^{4}$, \\ Kinichi Hotta ${ }^{1}$, Kenichiro Imai ${ }^{1}$, Masaki Tanaka ${ }^{1}$, Naomi Kakushima ${ }^{1}$ and Hiroyuki Ono ${ }^{1}$
}

\begin{abstract}
A 58-year-old man, who had presented with a large cyst between the pancreatic tail and splenic hilum 6 years previously, was referred to our hospital with exacerbation of abdominal distention. Computed tomography revealed a well-demarcated, unilocular cyst, with a beak sign for the pancreas, without wall thickening or nodules suggestive of a non-neoplastic cyst. Compared with 6 years previously, the cyst had increased in size from $14.7 \mathrm{~cm}$ to $19.5 \mathrm{~cm}$, and the serum carcinogenic antigen $19-9$ level had increased from $635 \mathrm{U} / \mathrm{mL}$ to $1,918 \mathrm{U} / \mathrm{mL}$. To prevent spontaneous rupture, laparotomy was performed, and the cyst was pathologically diagnosed as a splenic epithelial cyst.
\end{abstract}

Key words: splenic cyst, epithelial cyst, CA19-9, diagnosis, follow-up, resection

(Intern Med 55: 2629-2634, 2016)

(DOI: 10.2169/internalmedicine.55.6970)

\section{Introduction}

Splenic cysts are uncommon entities and classified as parasitic or nonparasitic cysts $(1,2)$. The latter are further divided into true cysts, those lined with epithelium or endothelium, and false cysts, those not lined with epithelium $(1,2)$. Epithelial cysts were reported in $0.07 \%$ of 42,327 autopsies (1). They are primarily benign and can be generally differentiated from malignant variants by clinical images $(3,4)$, including various types of cysts, such as epidermoid cyst, dermoid cyst, and lymphoepithelial cyst (2). However, epithelial cysts are occasionally accompanied by increased levels of serum tumor markers $(2,5)$, which can impede their diagnosis. They occasionally cause complications, such as rupture $(5,6)$, infection (7), and bleeding $(5,6)$, which can be lethal. For these reasons, epithelial cysts, especially large cysts, are often treated by prophylactic surgery. Therefore, the natural history of epithelial cysts has not been previously reported. Epithelial cysts are not specific to the spleen. They can also develop at the pancre- atic tail, with similar characteristics regarding age, image findings, and elevated serum tumor markers (8-10). We herein describe a patient with a large splenic cyst, which was difficult to differentiate from a cyst of pancreatic origin, who was followed up for 6 years. The cyst was eventually surgically resected due to an increase in size and exacerbation of the patient's symptoms.

\section{Case Report}

A 52-year-old man was referred to our hospital for an investigation of a cystic lesion located between the pancreatic tail and splenic hilum. The cyst was accompanied by pain in the left-upper abdomen. Computed tomography (CT) revealed a well-demarcated, unilocular cyst $(14.4 \times 11.6 \times 14.7$ $\mathrm{cm}$ ), with a beak sign for the pancreas, but without wall thickening or mural nodules (Fig. 1). Magnetic resonance imaging (MRI) demonstrated high-intensity signals on both T1- and T2-weighted images, thus suggesting a concentration of the fluid with the protein rich contents, and no obvious communication with the pancreatic duct on magnetic

${ }^{1}$ Division of Endoscopy, Shizuoka Cancer Center, Japan, ${ }^{2}$ Division of Hepato-Biliary-Pancreatic Surgery, Shizuoka Cancer Center, Japan, ${ }^{3}$ Division of Pathology, Shizuoka Cancer Center, Japan and ${ }^{4}$ Division of Diagnostic Radiology, Shizuoka Cancer Center, Japan

Received for publication December 11, 2015; Accepted for publication January 24, 2016

Correspondence to Dr. Hiroyuki Matsubayashi, h.matsubayashi@scchr.jp 
A

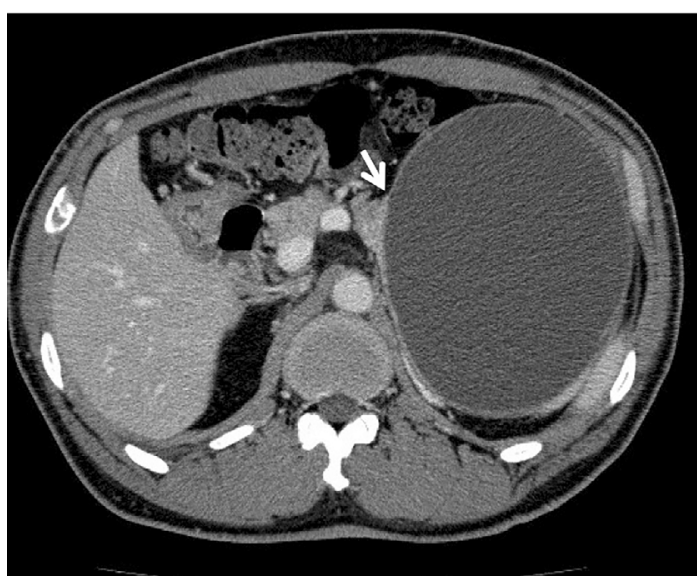

B

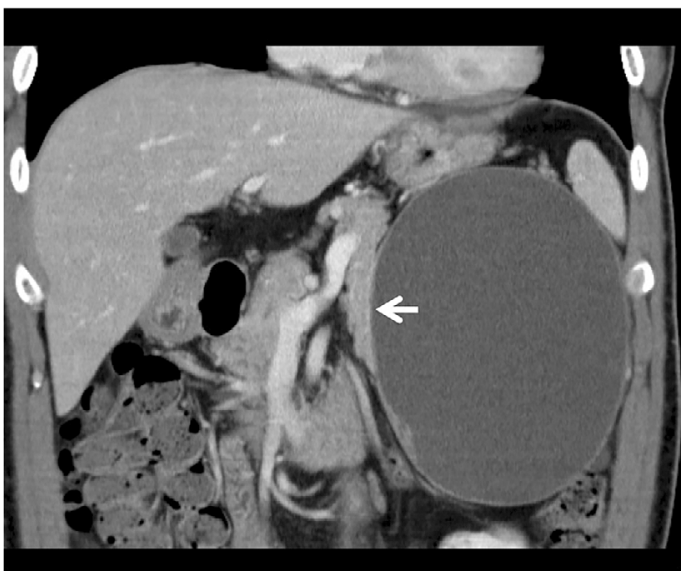

Figure 1. Enhanced computed tomography (CT) [horizontal (A) and coronal (B) views] at the initial presentation showing an unilocular cyst, $14.7 \mathrm{~cm}$ in maximum diameter, in the upper left quadrant with a beak sign in the pancreas (small arrow).

A

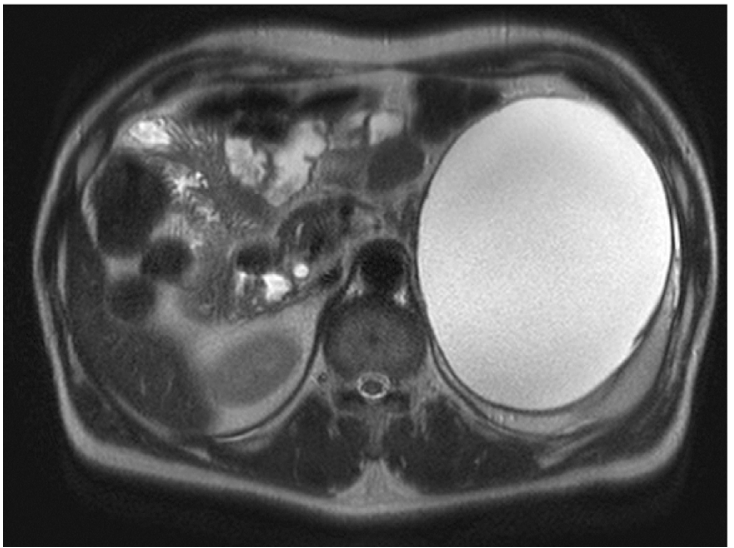

B

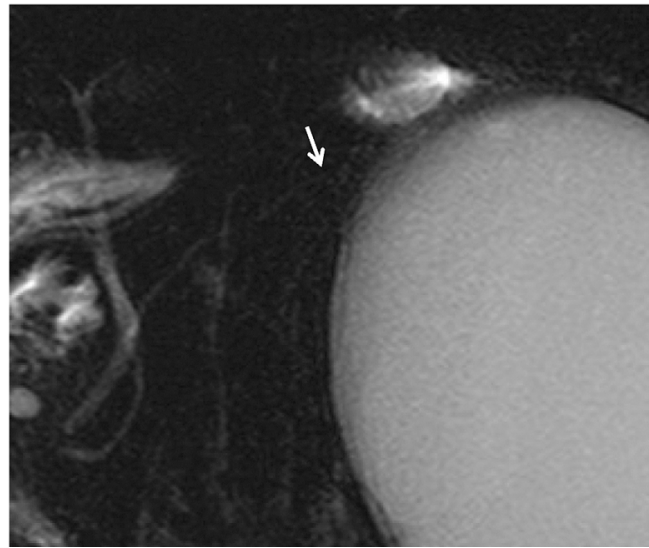

Figure 2. A T2-weighted magnetic resonance image (MRI) at the initial presentation showing a very high-intensity signal within the cyst $(\mathrm{A})$. Magnetic resonance cholangiopancreatography (MRCP) showing no obvious communication between the pancreatic duct and the cyst (arrow pointing to the visible end of the main pancreatic duct) $(B)$.

resonance cholangiopancreatography (MRCP) (Fig. 2). The patient had a history of diabetes mellitus and hypertension, but his family history was unremarkable. His condition was uneventful until this onset and negative for findings suggestive of a parasitic infection. Although the cyst was large and associated with an elevated level of serum carbohydrate antigen 19-9 (CA-19-9) (635 U/mL, normal: <37 U/mL), a nonneoplastic cyst (11) was strongly suspected, and the patient selected observation rather than surgery at that time.

However, 6 years later, the patient was again referred due to exacerbation of abdominal distension, leading to fears that the cyst had ruptured. He requested endoscopic cystic drainage from the stomach (12). During the intervening period, the patient had been in good health and denied any traumatic episodes. The serum CA19-9 level was elevated to $1,918 \mathrm{U} / \mathrm{mL}$, and the cyst had increased in size to $19.5 \mathrm{~cm}$ $(18.3 \times 14.8 \times 19.5 \mathrm{~cm})$ (Fig. 3). The CT and MRI findings were mostly unchanged, except for the size of the cyst. An endoscopic ultrasound (EUS) image showed an echolucent fluid-containing lesion attached to the pancreas, without septa or calcification (Fig. 4). These imaging findings and the elevated level of serum CA19-9 strongly suggested an epithelial cyst, either epidermoid (5) or lymphoepithelial (11), of the pancreas or spleen. Intra-abdominal leakage of cystic fluid may cause severe complications $(11,13,14)$, and surgery rather than endoscopic cystic drainage was strongly recommended (12).

On laparotomy, the cystic mass was adhered to the spleen and easily detachable from the pancreas and other surrounding viscera. Thus, splenectomy was performed. The cyst was filled with 2,500 $\mathrm{mL}$ of serous brown fluid. Rapid cytology of the fluid revealed no atypical cells. The cyst was pathologically proven to be of splenic origin. It was covered with a single layer of squamous epithelium and was diag- 
A

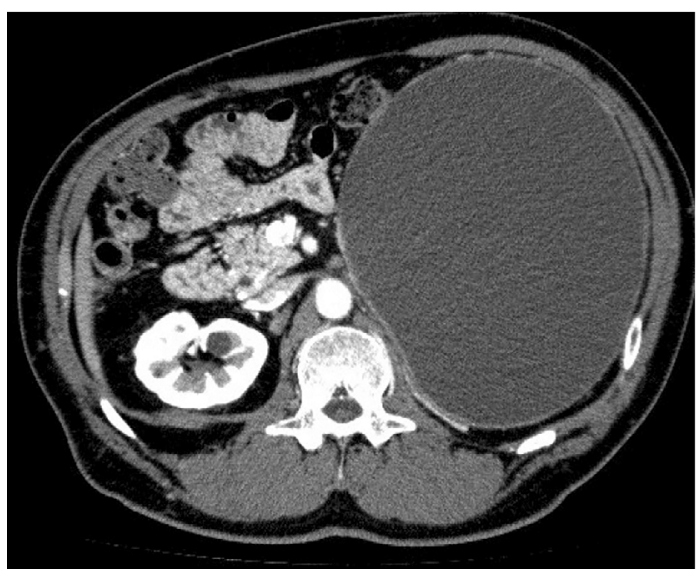

B

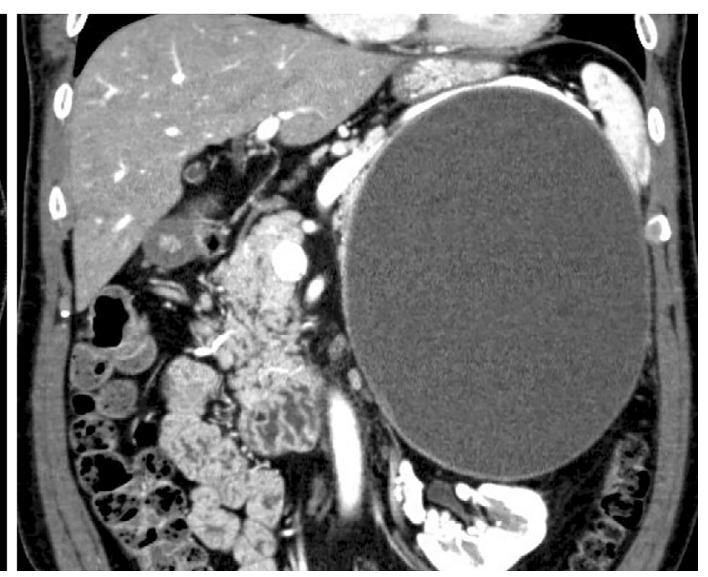

Figure 3. Enhanced CT of the horizontal (A) and coronal (B) views at the second presentation, showing a growing cyst, $19.5 \mathrm{~cm}$ in diameter.

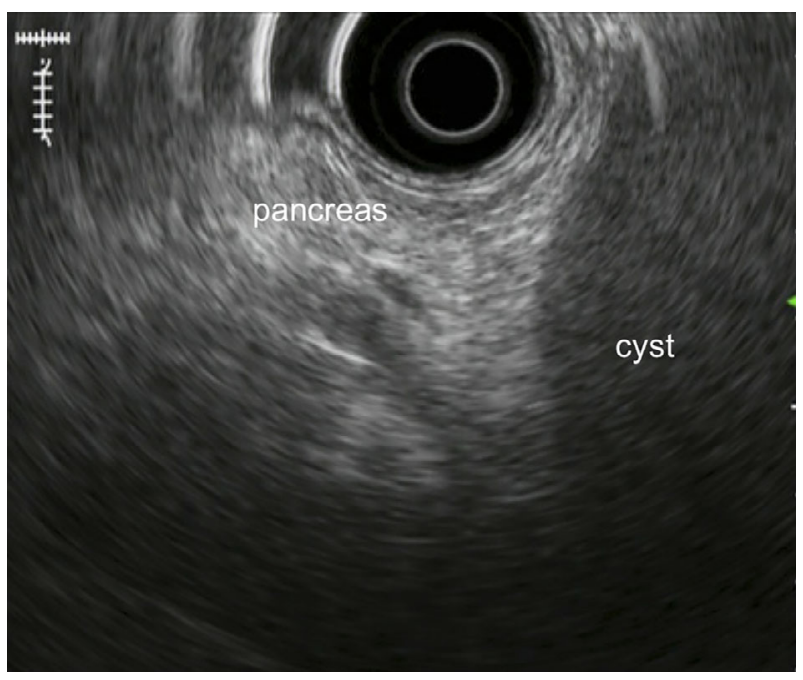

Figure 4. Endoscopic ultrasonography (EUS) showing the cyst attached to the pancreas.

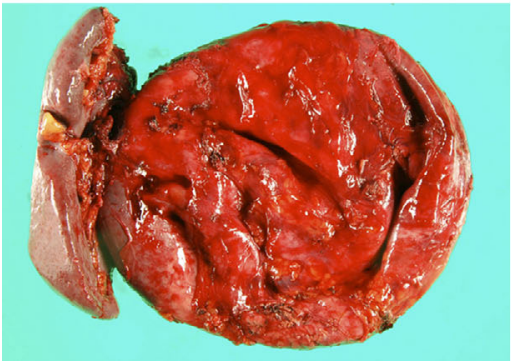

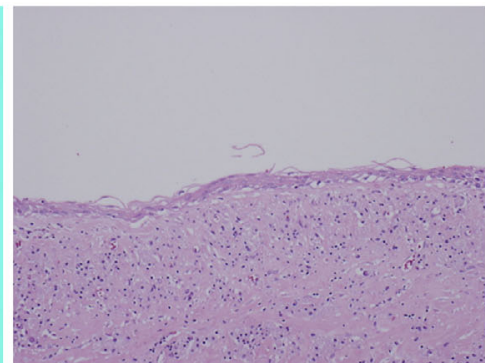

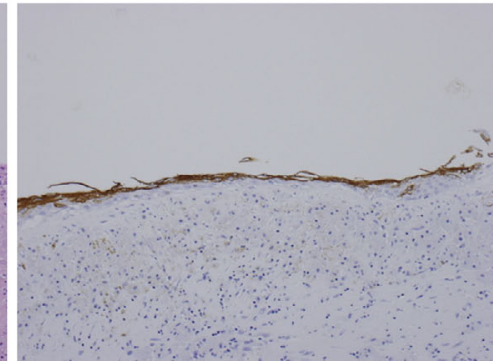

Figure 5. The gross appearance of the en bloc resected cyst and spleen (A) and histology of the cyst wall (B). The cyst was incised and decompressed by excluding $2,500 \mathrm{~mL}$ of fluid content (A). A stratified, flattened squamous epithelium was visible on the cystic wall (Hematoxylin and Eosin staining, 100x) (B) and immunohistochemically positive for CA19-9 (100x) (C)

nosed as an epithelial cyst of the spleen (Fig. 5). The postoperative course was uneventful, and the serum CA19-9 level decreased to within the normal range in 2 months. During the 2-year postoperative follow-up, there was no evidence of recurrence or other associated complications.

Discussion

With the recent expansion of medical screening systems, the detection of splenic lesions has increased by 0.5 - 
Table. Reported Cases of Splenic True Cysts Larger than $15 \mathrm{~cm}(\mathrm{n}=\mathbf{2 2})$.

\begin{tabular}{|c|c|c|c|c|c|c|c|c|}
\hline Reference No. & Sex & Age & $\begin{array}{l}\text { Size } \\
(\mathrm{cm})\end{array}$ & Diagnosis & Symptom & $\begin{array}{l}\text { CA19-9 } \\
(\mathrm{U} / \mathrm{mL})\end{array}$ & Complication & Treatment \\
\hline 30 & $\mathrm{~F}$ & 29 & 18 & mesothelial & abdominal pain & NA & none & splenectomy \\
\hline 31 & $\mathrm{~F}$ & 21 & 16 & epithelial & abdominal pain & 830 & none & splenectomy \\
\hline 32 & $\mathrm{~F}$ & 12 & 20 & epidermoid & abdominal pain & NA & none & splenectomy \\
\hline 23 & $\mathrm{~F}$ & 16 & 16 & epithelial & abdominal pain & NA & none & hemisplenectomy \\
\hline 24 & $\mathrm{~F}$ & 26 & 16 & epidermoid & abdominal pain & 217 & none & $\begin{array}{l}\text { laparoscopic } \\
\text { splenectomy }\end{array}$ \\
\hline 33 & $\mathrm{M}$ & 22 & 18 & epithelial & $\begin{array}{l}\text { heavy feeling in } \\
\text { stomach }\end{array}$ & 502 & none & splenectomy \\
\hline 34 & $\mathrm{~F}$ & 32 & 20 & non-parasitic & abdominal pain & NA & none & splenectomy \\
\hline 35 & $\mathrm{~F}$ & 19 & 18 & epithelial & abdominal pain & 273 & none & $\begin{array}{l}\text { laparoscopic } \\
\text { splenectomy }\end{array}$ \\
\hline 36 & $\mathrm{~F}$ & 18 & 19 & epidermoid & $\begin{array}{l}\text { abdominal } \\
\text { fullness }\end{array}$ & 122 & none & $\begin{array}{l}\text { laparoscopic } \\
\text { splenectomy }\end{array}$ \\
\hline 37 & $\mathrm{~F}$ & 41 & 20 & epidermoid & abdominal pain & NA & none & splenectomy \\
\hline 21 & $\mathrm{~F}$ & 32 & 18 & epidermoid & abdominal pain & NA & ruptured & $\begin{array}{l}\text { laparoscopic } \\
\text { splenectomy }\end{array}$ \\
\hline 38 & $\mathrm{~F}$ & 15 & 15 & epithelial & $\begin{array}{l}\text { abdominal } \\
\text { fullness }\end{array}$ & NA & none & splenectomy \\
\hline 39 & M & 19 & 15 & epithelial & $\begin{array}{l}\text { abdominal } \\
\text { distension }\end{array}$ & NA & none & partial splenectomy \\
\hline 28 & $\mathrm{~F}$ & 23 & 17 & non-parasitic & abdominal pain & NA & $\begin{array}{c}\text { infected } \\
\text { (Staphylococcus } \\
\text { aureus) }\end{array}$ & $\begin{array}{l}\text { aspiration, } \\
\text { splenectomy }\end{array}$ \\
\hline 40 & - & 14 & 20 & epidermoid & $\begin{array}{l}\text { abdominal } \\
\text { distension }\end{array}$ & NA & none & $\begin{array}{l}\text { laparoscopic } \\
\text { splenectomy }\end{array}$ \\
\hline 40 & - & 11 & 18 & epidermoid & abdominal pain & NA & none & $\begin{array}{l}\text { laparoscopic } \\
\text { splenectomy }\end{array}$ \\
\hline 41 & $\mathrm{~F}$ & 25 & 18 & epidermoid & epigastric pain & NA & none & $\begin{array}{l}\text { laparoscopic } \\
\text { splenectomy }\end{array}$ \\
\hline 42 & $\mathrm{~F}$ & 18 & 20 & epidermoid & abdominal pain & 88 & none & $\begin{array}{l}\text { laparoscopic } \\
\text { splenectomy }\end{array}$ \\
\hline 43 & $\mathrm{~F}$ & 22 & 25 & epithelial & abdominal pain & 66 & none & $\begin{array}{l}\text { laparoscopic } \\
\text { splenectomy }\end{array}$ \\
\hline 44 & $\mathrm{M}$ & 9 & 21 & epidermoid & abdominal pain & NA & none & $\begin{array}{l}\text { laparoscopic } \\
\text { splenectomy }\end{array}$ \\
\hline 45 & $\mathrm{~F}$ & 30 & 20 & epidermoid & liver dysfunction & 491 & none & splenectomy \\
\hline Current Case & $\mathrm{M}$ & 58 & 19.5 & epithelial & abdominal pain & 1918 & none & splenectomy \\
\hline
\end{tabular}

$2 \%$ (15). Primary splenic epithelial cysts are uncommon, with only 800 cases reported in the English literature (2). The natural history of these cysts remains unclear because most reported cases have been surgically resected, rather than followed up, to prevent spontaneous rupture, infection, and bleeding (5-7). In the present case, the splenic epithelial cyst, the origin of which was difficult to identify preoperatively, was associated with exacerbation of symptoms, elevated serum CA19-9 levels, and an increased size after 6 years of follow-up.

Concerning the preoperative diagnosis of the current case, an epithelial cyst (10), including epidermoid (8) or lymphoepithelial $(9,11)$ cysts, was strongly suspected due to the extremely high level of serum CA19-9 (2, 5, 8, 9).

Because inner epithelial cells of the cyst produce CA19-9, which is retained within the cyst, increased intracystic pressure is thought to move the exuding of CA19-9 into the bloodstream through the surrounding splenic tissues. The level was disproportionate to the negative imaging findings and suggestive of malignancy. However, the origin of the cyst (pancreatic or splenic) could not be determined. On CT images, the beak sign (16) is often used to differentiate the origin of a cyst not attached to adjacent organs, as was performed in the current case (Fig. 1, 3). A significant trend may be observed in the cyst's size. According to a literature survey, non-neoplastic epithelial cysts of the pancreas tend to be smaller (mostly $<12 \mathrm{~cm})(8-10)$ than those of the spleen (average $14.3 \mathrm{~cm}(17))(\geq 15 \mathrm{~cm}$, Table). Caution is needed when judging the organ of origin of non-neoplastic cysts attached to both the pancreas and the spleen in clinical images, especially when they are relatively small. The origin can include the gastric wall and mesentery.

If we presume that the current cyst had an ellipsoid body, then the volume of the cyst at the time of the initial presentation was 1,285 mL. After 6 years, it was 2,764 mL, which was nearly the amount of fluid surgically aspirated from the 
cyst. Within the 6 years, the volume of the cyst increased more than twice that of the original volume (doubling time: 1,832 days), and this was accompanied by a parallel increase in the level of serum CA19-9 (635 to $1,918 \mathrm{U} / \mathrm{mL}$ ). Branch duct type, intraductal papillary mucinous neoplasms of more than $3 \mathrm{~cm}$ in size typically develop into cysts quite slowly (18). Although data are available for only one case (the current case), the speed of growth of splenic epithelial cysts may be faster than that of cystic neoplasms. Thus, to avoid potential critical events, surgical treatment is recommended for splenic epithelial cysts.

The indications for surgical treatment of splenic epithelial cysts have generally been a symptomatic cyst or an asymptomatic cyst of $\geq 5 \mathrm{~cm}(17,19)$. Observation is recommended for small, asymptomatic cyst (17), as spontaneous regression can be expected (20). However, this agreement is based on the facility of surgical treatment, rather than solid data. According to recent reviews, the incidence of overall complications in cases of splenic epithelial cysts was 5.2$8.5 \%(21,22)$, and ruptured cysts ranged in size from 5.5 $\mathrm{cm}$ to $15 \mathrm{~cm}$ or more $(20,23,24)$. In an analysis of 23 splenic epithelial cysts, the average size was $14.3 \mathrm{~cm}$ (range: $1-25 \mathrm{~cm})$, and none of the cysts were associated with complications, including rupture and infection (17). In a survey of PubMed data on splenic epithelial cysts of $\geq 15 \mathrm{~cm}$ in size, only 2 of $22(9.1 \%)$ patients had complications, despite complaints in all 22 cases $(22,25)$ (Table). Thus, the incidence of splenic epithelial cysts appears to be rare. Simply coughing during an asthma attack can cause cystic rupture (26). Small cysts $(5 \mathrm{~cm})$ may spontaneously rupture (27), leading to life-threatening events. In cases of congenital cysts, rupture may occur in infants who often tumble or fall on their stomach (17). Cystic rupture is also common in pregnant women with limited abdominal space (28). The recent surgical trend has shifted from laparotomy to lessinvasive, laparoscopic splenectomy. Although cystic decapsulation occasionally causes recurrences, partial laparoscopic splenectomy is excellent in preserving the splenic function $(25,29)$. Laparoscopic splenectomy also facilitates prophylactic surgery, rather than observation, at the time of the initial diagnosis of a splenic epithelial cyst.

In conclusion, we described a case of a giant splenic epithelial cyst, which grew rapidly and was associated with exacerbated symptoms after 6 years of follow-up. Caution is required when diagnosing the organ of origin of epithelial cysts. Less invasive treatment, possibly laparoscopic partial splenectomy, should be applied in cases with a definitive preoperative diagnosis.

The authors state that they have no Conflict of Interest (COI).

\section{References}

1. Robbins FG, Yellin AE, Lingua RW, Craig JR, Turrill FL, Mikkelsen WP. Splenic epidermoid cysts. Ann Surg 187: 231-235, 1978.
2. Ingle $\mathrm{SB}$, Hinge Ingle $\mathrm{CR}$, Patrike $\mathrm{S}$. Epithelial cysts of the spleen: a minireview. World J Gastroenterol 20: 13899-13903, 2014.

3. Ohe C, Sakaida N, Yanagimoto Y, et al. A case of splenic lowgrade mucinous cystadenocarcinoma resulting in pseudomyxoma peritonei. Med Mol Morphol 43: 235-240, 2010.

4. Kamaya A, Weinstein S, Desser TS. Multiple lesions of the spleen: differential diagnosis of cystic and solid lesions. Semin U1trasound CT MR 27: 389-403, 2006.

5. Matsubayashi H, Kuraoka K, Kobayashi Y, et al. Ruptured epidermoid cyst and haematoma of spleen: a diagnostic clue of high levels of serum carcinoembryonic antigen, carbohydrate antigen 19-9 and Sialyl Lewis x. Dig Liver Dis 33: 595-599, 2001.

6. Starr FN. Blood Cyst of the spleen: intracapsular rupture. Ann Surg 98: 919-921, 1933.

7. Rafailidis SF, Ballas KD, Marakis GN, et al. Epidermoid splenic cyst presented as huge splenic abscess: a case report. Acta Chir Belg 107: 449-451, 2007.

8. Kadota K, Kushida Y, Miyai Y, et al. Epidermoid cyst in an intrapancreatic accessory spleen: three case reports and review of the literatures. Pathol Oncol Res 16: 435-442, 2010.

9. Raval JS, Zeh HJ, Moser AJ, et al. Pancreatic lymphoepithelial cysts express CEA and can contain mucous cells: potential pitfalls in the preoperative diagnosis. Mod Pathol 23: 1467-1476, 2010.

10. Assifi MM, Nguyen PD, Agrawal N, et al. Non-neoplastic epithelial cysts of the pancreas: a rare, benign entity. J Gastrointest Surg 18: 523-531, 2014.

11. Matsubayashi H, Sugimoto S, Kishida Y, et al. Rupture of a suspected pancreatic lymphoepithelial cyst causing chemical peritonitis after endoscopic ultrasound guided-fine needle aspiration. Endoscopy 46 (Suppl 1) UCTN: E51-E52, 2014.

12. Yasuda I, Iwata K, Mukai T, Iwashita T, Moriwaki H. EUS-guided pancreatic pseudocyst drainage. Dig Endosc 21 Suppl 1: S82-S86, 2009.

13. Panossian DH, Wang $\mathrm{N}$, Reeves CD, Weeks DA. Epidermoid cyst of the spleen presenting as a generalized peritonitis. Am Surg 56: 295-298, 1990.

14. WEEKLY clinicopathological exercises. Rupture of spleen, probably through splenic cyst. N Engl J Med 243: 662-665, 1950.

15. Higaki K, Jimi A, Watanabe J, Kusaba A, Kojiro M. Epidermoid cyst of the spleen with CA19-9 or carcinoembryonic antigen productions: report of three cases. Am J Surg Pathol 22: 704-708, 1998.

16. Kim HJ, Lee DH, Lim JW, Ko YT, Kim KW. Exophytic benign and malignant hepatic tumors: CT imaging features. Korean J Radiol 9: 67-75, 2008.

17. Morgenstern L. Nonparasitic splenic cysts: pathogenesis, classification, and treatment. J Am Coll Surg 194: 306-314, 2002.

18. Kobayashi G, Fujita N, Noda Y, et al. Mode of progression of intraductal papillary-mucinous tumor of the pancreas: analysis of patients with follow-up by EUS. J Gastroenterol 40: 744-751, 2005.

19. Kenney CD, Hoeger YE, Yetasook AK, et al. Management of nonparasitic splenic cysts: does size really matter? J Gastrointest Surg 18: 1658-1663, 2014.

20. Stoidis CN, Spyropoulos BG, Misiakos EP, Fountzilas CK, Paraskeva PP, Fotiadis CI. Spontaneous regression of a true splenic cyst: a case report and review of the literature. Cases $\mathrm{J} 2$ : 8730, 2009.

21. Kiriakopoulos A, Tsakayannis D, Papadopoulos S, Linos D. Laparoscopic management of a ruptured giant epidermoid splenic cyst. JSLS 9: 349-351, 2005.

22. Nakao A, Saito S, Yamano T, et al. Dermoid cyst of the spleen: report of a case. Surg Today 29: 660-662, 1999.

23. Kimber C, Pierro A, Drake D, Kiely E, Spitz L. Hemisplenectomy for giant splenic cysts in children. Pediatr Surg Int 14: 116-118, 1998.

24. Sakamoto Y, Yunotani S, Edakuni G, Mori M, Iyama A, Miyazaki 
K. Laparoscopic splenectomy for a giant splenic epidermoid cyst: report of a case. Surg Today 29: 1268-1272, 1999.

25. Lee SH, Lee JS, Yoon YC, Hong TH. Role of laparoscopic partial splenectomy for tumorous lesions of the spleen. J Gastrointest Surg 19: 1052-1058, 2015.

26. Fragandreas G, Papadopoulos S, Gerogiannis I, et al. Epithelial splenic cysts and life-threatening splenic rupture. Chirurgia $(\mathrm{Bu}-$ cur) 106: 519-522, 2011.

27. Lam CM, Yuen ST, Yuen WK. Hemoperitoneum caused by spontaneous rupture of a true splenic cyst. Hepatogastroenterology 45: 1884-1886, 1998.

28. Rotas M, Ossowski R, Lutchman G, Levgur M. Pregnancy complicated with a giant splenic cyst: a case report and review of the literature. Arch Gynecol Obstet 275: 301-305, 2007.

29. Mertens J, Penninckx F, DeWever I, Topal B. Long-term outcome after surgical treatment of nonparasitic splenic cysts. Surg Endosc 21: 206-208, 2007.

30. Kuwabara S, Hohjoh H, Nakano M, Ebihara Y, Toyama K. Mesothelial splenic cyst. Intern Med 32: 672-674, 1993.

31. Terada T, Yasoshima M, Yoshimitsu Y, Nakanuma Y. Carbohydrate antigen 19-9 producing giant epithelial cyst of the spleen in a young woman. J Clin Gastroenterol 18: 57-61, 1994.

32. Baglaj M, Czernik J. Epidermoid cyst in a wandering spleen. Pediatr Surg Int 14: 113-115, 1998.

33. van Lacum MW, Hessels RA, Kremer GD, Jaspers CA. A splenic cyst and a high serum CA 19-9: a case report. Eur J Intern Med 11: 104-107, 2000

34. Avital S, Kashtan H. A large epithelial splenic cyst. N Engl J Med 349: 2173-2174, 2003.

35. Madia C, Lumachi F, Veroux M, et al. Giant splenic epithelial cyst with elevated serum markers CEA and CA 19-9 levels: an incidental association? Anticancer Res 23: 773-776, 2003.

36. Yagi $\mathrm{S}$, Isaji $\mathrm{S}$, Iida $\mathrm{T}$, et al. Laparoscopic splenectomy for a huge splenic cyst without preoperative drainage: report of a case. Surg Laparosc Endosc Percutan Tech 13: 397-400, 2003.

37. Casaccia M, Saltalamacchia L, Panaro F, et al. Total splenectomy for a recurrent giant splenic cyst. G Chir 25: 390-393, 2004 (in Japanese, Abstract in English).

38. Macheras A, Misiakos EP, Liakakos T, Mpistarakis D, Fotiadis C, Karatzas G. Non-parasitic splenic cysts: a report of three cases. World J Gastroenterol 11: 6884-6887, 2005.

39. Itamoto $\mathrm{T}$, Fukuda $\mathrm{S}$, Tashiro $\mathrm{H}$, Ohdan $\mathrm{H}$, Asahara $\mathrm{T}$. Radiofrequency-assisted partial splenectomy with a new and simple device. Am J Surg 192: 252-254, 2006.

40. Fisher JC, Gurung B, Cowles RA. Recurrence after laparoscopic excision of nonparasitic splenic cysts. J Pediatr Surg 43: 16441648, 2008.

41. Dan D, Bascombe N, Harnanan D, Hariharan S, Naraynsingh V. Laparoscopic management of a massive splenic cyst. Asian J Surg 33: 103-106, 2010.

42. Vo QD, Monnard E, Hoogewoud HM. Epidermoid cyst of the spleen. BMJ Case Rep 2013: bcr2013009707, 2013.

43. Yoh T, Wada S, Kobayashi A, et al. Laparoscopic splenectomy for a large multilocular splenic cyst with elevated CA19-9: report of a case. Int J Surg Case Rep 4: 319-321, 2013.

44. Pastore V, Bartoli F. A report of a giant epidermoid splenic cyst. Afr J Paediatr Surg 11: 67-70, 2014.

45. Matsumoto S, Mori T, Miyoshi J, et al. Huge splenic epidermoid cyst with elevation of serum CA19-9 level. J Med Invest 62: 8992, 2015.

The Internal Medicine is an Open Access article distributed under the Creative Commons Attribution-NonCommercial-NoDerivatives 4.0 International License. To view the details of this license, please visit (https://creativecommons.org/licenses/ by-nc-nd/4.0/).

(C) 2016 The Japanese Society of Internal Medicine http://www.naika.or.jp/imonline/index.html 